\title{
A Network and its Ephemera before the Internet: The Hidden Treasures and Clear Challenges of Apazines
}

SubCULTURES PRODUCE MANY TYPeS of ephemera, and they often have linguistic conventions that accompany them. To those outside, words such as "minac," "egoboo," "annish," and "akicif” have little meaning, but they are all examples from a particular subculture's ephemeral publication that even goes by a name that is obscure: the apazine. What is an apazine, why are they increasingly important, and how is this type of ephemeral material made accessible? These questions can be answered by looking at how apazines developed and the characteristics of the subculture of science fiction fandom that created them.

Message boards, listservs, and other forms of communication on the Internet are so familiar that we take for granted the ability to connect to people who share similar interests. Before the Internet, however, it was not as easy to feel connected to a group, particularly if one's interests were at all outside the mainstream. But people did manage to find ways to communicate collectively. Science fiction fans developed an extensive communication network before the advent of the Internet through informal mailing groups called Amateur Press Associations, or apas.

An apa is a group or a club with limited membership, sometimes about a dozen members, or up to a few dozen in the case of the larger apas. Members communicate with one another by creating material, such as messages, fiction, or art, then sending enough copies for everyone in the group to a person designated the "Central Mailer," who collates the information and then mails a packet containing all of the contributions to each of the members. Science fiction fandom developed close-knit and elaborately documented apas beginning in the late 1930s as an offshoot of the kind of creative activity that produced fanzines. An apazine is the zine, or written content, created by a member for distribution in the mailing.

The result is an enormous body of work written by science fiction fans that was never intended for public distribution. It has nearly every feature we now recognize 
from group communication on the Internet. Apazines are a kind of "Internet on paper," a social network from a time before the term had any currency-Web negative 2.0. In many cases, the interest that brings people to apas is seldom discussed, in favor of topics from contributors' personal lives, relationships, and jobs. In other cases, original fiction, art, and drama are created for apazines by fans who later became professionals.

This original material is one factor that makes apazines such a rich source for scholarly research. The University of Iowa recently obtained the Horvat Collection of Science Fiction Fanzines, which contains a large number of apazines. Several members of the English faculty at Iowa specialize in science fiction research, and along with their graduate students they have already begun to form plans for utilizing these resources. A quick look at some of the material will explain why.

Within the Horvat collection is a substantial run of the apazine APA-5, an apa devoted largely to comics. The cover art for the APA-5 mailing number 24 , from 1973 , is by a high school student named Frank Miller. The drawing is of an ancient warrior holding a sword and shield. The artist seems to have an affinity for this type of image: this is the Frank Miller who went on to create the graphic novel 300, recently adapted into a popular film. He is considered one of the most innovative comic artists of our time, still active and successful. His contributions to APA-5 span many of his most formative years and include not only his early comic art but also his writings about his life, art, films he watched, and books he read. This is the type of material a researcher often hopes to find in a collection of personal papers. But Miller's early work is only one memorable feature of APA-5, as other members went on to found Dark Horse Comics, now the third largest comic-book company in the industry. This rich interaction of personalities at a formative stage makes apas particularly appealing for research.

The list of well-known science fiction authors and personalities who have contributed to apazines reads like a Who's Who of the genre: Forrest J. Ackerman, Gregory Benford, James Blish, Jack Chalker, Damon Knight, Frederik Pohl, and Robert Silverberg, among others. Many were at one time members of the first science fiction apa, the Fantasy Amateur Press Association (FAPA), begun in 1937 and still continuing to this day. FAPA mailings document nearly the entire history of American science fiction, and include contributions in the form of apazines from all of its members, which sounds relatively straightforward. But, in reality, FAPA mailings are among the largest and most complex in the genre. For example, mailing \#100 in 1962 consisted of a total of 1,219 pages. This is unusual even by apazine standards, but it does indicate the level of dedication apa members often felt. ${ }^{1}$

1. Bernadette Bosky, "Amateur Press Associations: Intellectual Society and Social Intellectualism," in Science Fiction Fandom, ed. Joe Sanders (Westport, Conn.: Greenwood Press, 1994), 184. 
A closer examination of the common features of apazines can provide direction for their care and cataloging. Most apa mailings come with some type of cover artwork. Inside, there is a listing that looks much like a table of contents but, in fact, lists the names of the apazines and usually the name of the zines' creators, along with the page count for each zine. Typically some administrative information and guidelines developed by the Central Mailer (the apa member who puts each mailing together) are provided. There is also a roster where the apa members are identified by name and address, followed by information on the members of the official waitlist - those hoping to join when a current member leaves the group.

A member's zine can consist of anything he or she chooses to write. In some cases, there are creative materials: reviews of books or films, or tales from science fiction conventions. In many apas, though, science fiction topics are rare and the zines tend to be more personal in nature, sometimes to a quite intimate degree. All of this activity is played out through the central feature of an apazine: the mailing comments, where each member responds in writing to the content of the previous mailing.

An example from a long-running apa, Spectator, provides a sense of the type of conversation found in a sequence of mailing comments. In Spectator \#102, a fan named Wally Stoelting has this to say to Burnett Toskey: "I try to pick my fake names from favorite books by favorite authors. Tell me, why were my poems alien to your taste: quality, subject matter, or style?" The mimeographed reproduction of the page has rendered the text almost unreadable. A few months later in the next mailing, \#103, Toskey uses the mailing comments in his zine to reply to Stoelting: "Man, your repro is terrible, this time. Looks like you forgot to put ink in the mimeo. It won't print without ink, you know?" He then describes why he does not like any poetry, all of which is written in the hasty, typo-ridden style common to today's Internet messages.

This example is of a brief exchange, but mailing comments can also be extremely detailed and take up several pages for one comment back to one member. Now, imagine mailing comment after mailing comment, from all of the apa's members, month after month, and you begin to get a sense of just how much the structure of an apa mailing functioned almost exactly like a computer network. There were even frequent flame wars, just as there are online today. This was true even back in the early days of apas, as demonstrated by a conflict between two fans in the 1940s, Larry Shaw and Walter Daugherty.

Larry Shaw had a distinguished career as an editor of science fiction novels and also wrote some short stories. Walter Daugherty, who recently died at the age of 90 , 
was a prominent fan in Los Angeles who contributed to many apas. As participants in the tightly woven world of science fiction fandom in the 1940s, their paths were bound to cross numerous times. All was not collegial, however. Daugherty wrote an article for a January 1944 FAPA mailing titled "To Hell with You, Larry T. Shaw," which drew a response in the next FAPA from Shaw, with the straightforward title "Rats Will Eat You, Walter J. Daugherty.” He begins on the first page with the statement "Unfortunately, my opinion of Walter J. Daugherty is completely unprintable." That, however, is not nearly enough to stop him, as Shaw's entire six-page apazine is devoted to his rebuttal of Daugherty's criticisms, listed point-bypoint much like an e-mail response. The tone is bitter, mocking, and oddly familiar. Many ephemeral pamphlet publications are debates and verbal feuds carried on by two opposing parties. For anyone studying the early history of American science fiction, these names loom large in the development of fandom.

Since apa-style communications are so reminiscent of the Internet, it is natural to wonder what happened to them once online communication became widely available. The answer is that some are still active, still producing mailings on paper distributed to a mailing list. But much of the activity has moved online, as expected, and the apa culture did have a role in this transition. Many fans are interested in new technology and began communicating online well before the general public commonly did so, adapting the model of apa mailings to the new medium. They began logging in to corporate networks, such as General Electric's, in the 1980s, when corporations made their systems publicly available during off-hours overnight and users would pay by the hour to post messages on topic-driven message boards. The cheapest rates, still expensive by today's standards, began after eleven o'clock at night. Science fiction fandom easily made the transition to the new world of online communication. ${ }^{2}$

With such rich sources of cultural history lurking within these ephemeral publications, the question for librarians and archivists maintaining apazine collections is how best to make this material accessible for research and study. This is especially difficult given the complexity of content, along with apazines' highly personal appearance. Basic processing of a collection is relatively straightforward, as apas can be arranged by the name of the apa and then the order of mailings, which are usually clearly identified. This allows them to be rehoused on the shelf, but it does not help a researcher, who typically wants to find work by a specific author or personality. What is essentially needed is an index to provide access to personal names. But as with any ephemeral publication, indexing a collection of apazines is beyond the resources of many institutions.

2. Camille Bacon-Smith, Science Fiction Culture (Philadelphia: University of Pennsylvania Press, 2000), 112 . 
Today, one of the first options to consider is digitization. Creating an index means extracting names from the issues so that they can be searched. The key advantage to apas is the standardized form of the table of contents, listing the names of the contributors, the names of their zines, and the number of pages they submitted to the mailing. By scanning the table of contents from each mailing of an apa, the names can be recognized as text characters by a computer (i.e., "OCR'd") to become searchable. Applying metadata to the images enhances their searchability and would essentially generate an index dynamically. Using content management software, such as CONTENTdm, a search for "Frank Miller" would identify the issues to which he contributed, which in turn could be displayed as thumbnails of the contents pages containing the search terms.

Such a process might begin to open up the content of apas, but it is only a very basic first step. A continuing problem would be that of subject access-a search for Frank Miller may bring up dozens of hits revealing which issues of APA-5 contain his writings, but what was he writing about? Which issues marked key developments in his style relevant to his later work? Another significant problem is that a contributor index does not capture the ongoing conversations in the mailing comments-while it would be possible to discover that Frank Miller contributed to a mailing, it would be difficult to know to whom he addressed his comments in that issue. Human intervention is still required to do the hard work of researching these questions.

In today's environment, some would say the zines should just be digitized in their entirety, allowing topics and phrases to be searched in their full text. While that would certainly be beneficial to a number of researchers, there are many deterrents to doing so with apazines. The major obstacle is copyright: since apazines were not created before 1923, they are all essentially in copyright, and the rights would be difficult to specifically identify. But beyond that, there are issues related to the librarians' role as caretakers of these materials. The closed-network nature of apas created a safe, nonpublic forum for members to express intimate and personal details about their lives to other members. Conversations often turned to relationships (many formed within the social boundaries of fandom or even the specific apa) and frequently include discussion of sexual and romantic partnerships. Many of these apa contributors are still living and never considered that their writing might end up in publicly accessible collections. Access should certainly be provided to these materials for researchers and interested patrons; but good relations with the fan community also need to be maintained, which suggests that librarians should act with some measure of discretion as owners of material created in such close-knit communities.

While it is often a complicated situation, having to balance donor relations with public access is hardly new. In collections of personal papers, it is often the case that 
the donor may have consented to have his or her correspondence made available, but each of the correspondents probably did not. As with many of the materials in research collections, the key is sensitivity, particularly in collections with a substantial amount of material from the recent past.

If large-scale digitization is problematic, other approaches for bringing these collections to light need to be explored. One of the most important steps to improve access to these materials is increased institutional cooperation. There are major collections of apazines at several universities, including the University of Iowa; and, as tends to be the case with ephemeral publications, it is common to have gaps in titles or incomplete issues. If institutions work together to standardize descriptive terms, agree on levels of digitization, and share data among institutions, a comprehensive resource for scholars of science fiction can begin to be built. And working together means involving all of the groups who benefit from these collections-librarians and faculty, as well as the apazine creators and members of fandom, who may not necessarily view public institutions as the best repository for material traditionally kept within the confines of the subculture. If we can navigate between the needs of each of these constituencies, together we can identify how these materials are used and preserved.

There are many challenging issues to consider when working with apazines, not the least of which is what "minac" might be. It is shorthand for "minimum activity," an expectation for how much material apa members needed to produce to remain in the group. "Egoboo" is short for "ego boost" - a positive comment on someone's work provides an ego boost. "Annish" is the "annual issue," usually produced in the month that commemorates the first appearance of the zine, and bigger than other months' issues. And finally, "akicif" translates as "all knowledge is contained in fanzines," which, if true, certainly provides ample reason to unlock their contents for all potential users.

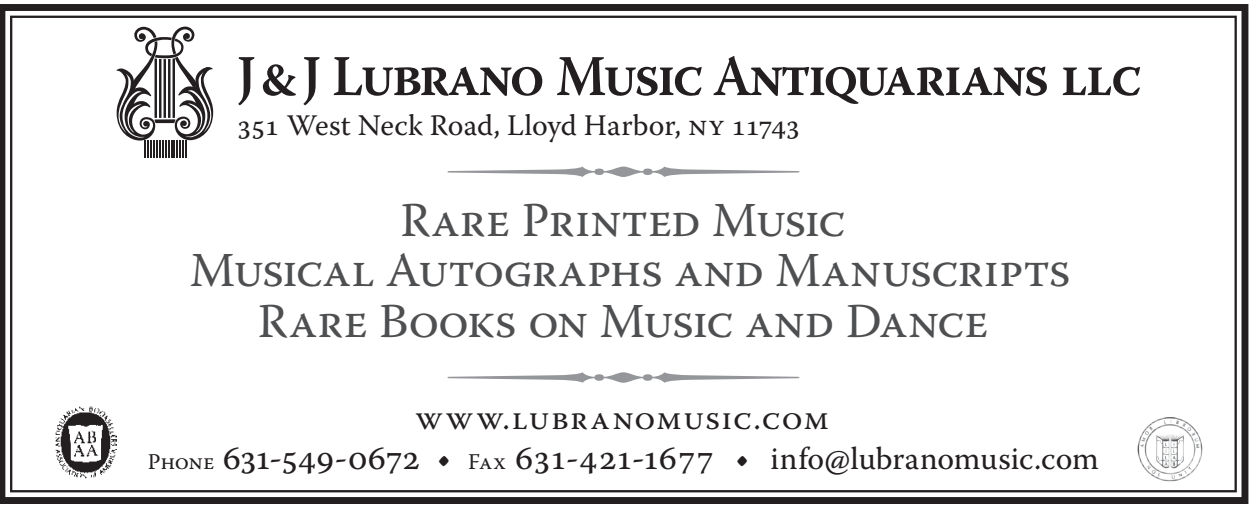

